\title{
SIFAT KIMIA DAN FISIK BAHAN UTAMA CONBLOCK RINGAN YANG MENGGUNAKAN AGREGAT SEKAM PADI
}

\author{
Chemical and Physical Properties of Main Substance of Lightweight Composite Cement Using Rice Husk \\ as Aggregat \\ Bakri
}

Lab. Pemanfaatan dan Pengolahan Hasil Hutan, Fakultas Kehutanan Universitas Hasanuddin

Jl. Perintis Kemerdekaan Km. 10 Tamalanrea, Makassar 90245

\begin{abstract}
This research aimed to assess the properties of main substances used to produce lightweight composite cement using rice husk as aggregate. Main substances used in this research consisted of Portland cement tipe I, lime, rice husk and rice husk ash. Portland cement tipe I, lime and rice husk obtained from local producers in Makassar, while rice husk ash obtained by burning rice husk conventionally in kiln drum and subsequently followed by burning in furnace of 1400 Barnsted Thermolyne Type at temperature $600^{\circ} \mathrm{C}$ for 2 hours. Chemical Content of the substances analyzed by adopted the analysis procedure in SNI 15-2049-2004. Alkalinity of Portland cement tipe I, silica of rice husk ash and $\mathrm{Na}_{2} \mathrm{O}$ dan $\mathrm{K}_{2} \mathrm{O}$ was categorized as low, while rice husk was categorized as reactive substance.
\end{abstract}

Key words: Portland cement tipe I, rick husk, rice husk ash, lime, lightweight composite cement

\section{PENDAHULUAN}

Bahan-bahan berlignoselulosa umumnya dapat dimanfaatkan sebagai bahan baku pembuatan komposit baik yang menggunakan matriks polimer sintetis seperti resin thermosetting maupun matriks keramik seperti semen. Salah satu bahan berlignoselulosa yang potensil dikembangkan sebagai agregat komposit semen yaitu sekam padi.

Sekam padi merupakan bahan berlignoselulosa yang mengandung silika tinggi. Silika sekam padi dalam bentuk kristalin (quartz dan opal) dan amorf terkonsentrasi pada bagian permukaan luar dan sedikit pada bagian dalam sekam (Jauberthie et al., 2000). Kandungan kimia sekam padi terdiri atas $50 \%$ selulosa, $25-30 \%$ lignin, dan $15-20 \%$ silika (Ismail \& Waliuddin, 1996). Porositas sekam padi yang sangat tinggi yaitu sekitar $79 \%$ menyebabkan sekam padi dapat menyerap air dalam jumlah yang banyak (Kaboosi, 2007). Namun demikian karena mengandung lignin dan silika yang cukup tinggi

Diterima: 29 Maret 2012; Disetujui: 13 Juni 2012

$\triangle$ Penulis korespondensi (corresponding author): bakribakri10@yahoo.com menyebabkan sekam padi sulit terdekomposisi oleh air dan jamur perusak dan pembusuk sehingga cocok digunakan sebagai agregat komposit semen.

Walaupun sekam padi dapat digunakan sebagai agregat komposit semen ringan, namun potensil menghasilkan reaksi alkali silika. Reaksi alkali silika pertama kali dilaporkan pada akhir tahun 1930 dan sekarang menjadi sangat terkenal di bidang konstruksi karena reaksi ini menyebabkan kerusakan pada struktur beton (Hicks, 2007).

Semen Portland mengandung ion alkali $\mathrm{Na}^{+}$ dan $\mathrm{K}^{+}$dalam sodium oksida $\left(\mathrm{Na}_{2} \mathrm{O}\right)$ dan potasium oksida $\left(\mathrm{K}_{2} \mathrm{O}\right)$ dengan persentase yang sangat kecil yaitu antara 0,2-1,1\%. Namun demikian ion-ion alkali ini akan terkonsentrasi pada larutan dalam pori pasta semen ketika bergabung dengan ion hidroksil $\left(\mathrm{OH}^{-}\right)$sehingga dapat menaikkan $\mathrm{pH}$ larutan dalam pori pasta semen menjadi 13-14 (Bertolini et al., 2004).

Jika campuran pasta semen mengandung agregat reaktif yaitu agregat yang memiliki kandungan silika maka senyawa dalam larutan alkali akan bereaksi dengan silika yang disebut sebagai reaksi alkali silika (ASR) (Kerenidis, 2007). ASR yang terjadi akan menghasilkan gel alkali silika 
dan jika gel ini menyerap air maka akan terjadi pengembangan yang mengakibatkan pasta semen retak (Freitag et al., 2003). Gel alkali silika yang terbentuk berada di sekeliling dan di dalam agregat (Thomas et al., 2007). Namun demikian ASR bukan faktor utama penyebab retak pada pasta semen sebab retak pada pasta semen bisa pula terjadi karena penyusutan pengeringan, tegangan akibat panas, cuaca, karat bahan penguat, komposisi campuran yang tidak sesuai, beban lebih, serta serangan kimia dari luar.

ASR hanya dapat terjadi karena adanya tiga komponen yaitu silika pada agregat, alkali tinggi pada semen Portland dan bahan lain yang dicampur dengan semen, dan air (kelembaban tinggi) (Malvar \& Lenke, 2006). Jika salah satu dari komponen ini dihilangkan maka ASR dapat dicegah. Agregat reaktif yang mengandung silika ditemukan pada arenite, argillite, chert, flint, gneiss, granite, greywacke, hornfels, quartz, arenite, quartzite sandstone, shale, silicified carbonate dan siltstone. Istilah reaktif merujuk pada agregat yang cenderung terurai karena bereaksi dengan alkali tinggi yang terdapat pada larutan dalam pori pasta semen atau beton untuk membentuk gel (Folliard et al., 2006).

Jumlah alkali dalam semen Portland yang dinotasikan sebagai $\mathrm{Na}_{2} \mathrm{O}_{\text {eq }}$ (equivalent soda) dalam persen dihitung berdasarkan rumus $\mathrm{Na}_{2} \mathrm{O}_{\text {eq }}=\mathrm{Na}_{2} \mathrm{O}$ $+0.658 \mathrm{Na}_{2} \mathrm{O}$. Walaupun persentase $\mathrm{Na}_{2} \mathrm{O}_{\text {eq }}$ dan $\mathrm{Na}_{2} \mathrm{O}$ sangat kecil dibandingkan dengan senyawa oksida lainnya dalam semen Portland tetapi dapat menaikkan alkalinitas yang tinggi pasta semen. Sumber utama ion hidroksil $\left(\mathrm{OH}^{-}\right)$pada pasta semen adalah dari kalsium hidroksida yang dihasilkan dari proses hidrasi semen. Semakin banyak kalsium hidroksida yang dihasilkan dari proses hidrasi dan semakin tinggi jumlah alkali dalam semen, maka semakin tinggi pula alkalinitas pasta semen. Untuk mengetahui kadar alkali yang aman pada larutan dalam pori pasta semen maka hanya alkali yang terdapat pada semen yang diperhitungkan sedangkan yang berasal dari bahan lain yang dapat meningkatkan alkali total pasta semen tidak diperhitungkan. Kerusakan beton atau komposit semen lainnya hanya terjadi pada semen yang memiliki kadar alkali tinggi yaitu yang memiliki lebih dari $1 \% \mathrm{Na}_{2} \mathrm{O}_{\mathrm{eq}}$. Sumber alkali semen adalah alkali yang terdapat pada permukaan butiran klinker yang secara normal memadat pada permukaan butiran klinker dan alkali yang terkunci di dalam butiran klinker yang memiliki struktur kristalin. Alkali yang berada sebagai sulfat pada permukaan butiran klinker akan larut dalam air dengan cepat sedangkan alkali yang terkunci dalam butiran klinker akan larut lebih lambat.

Penggantian sebagian semen atau supplementing cementitious material (SCM) oleh bahan pozzolan dalam campuran dapat dilakukan untuk memenuhi ketiga cara pengendalian ASR. Bertolini et al. (2004) mengemukakan bahwa penggunaan blast furnace slag, fly ash atau silica fume sebagai SCM pada persentase tertentu dapat mengurangi konsentrasi ion alkali pada semen sehingga menurunkan $\mathrm{pH}$ di bawah 13. Peranan lain bahan SCM yaitu akan menghasilkan CSH yang dapat memperkecil ukuran pori sehingga permeabilitas pasta semen berkurang.

SCM yang mulai dikembangkan saat ini selain silica fume dan fly ash adalah abu sekam padi (RHA). MoDOT (2003) menggunakan berbagai SCM seperti fly ash, silica fume dan slag sebagai SCM untuk mengatasi ASR yang menunjukkan bahwa beton yang dibuat tanpa SCM memiliki permeabilitas sedang, yang menggunakan SCM sebesar 15 dan $25 \%$ memiliki permeabilitas rendah dan yang menggunakan SCM sebesar 30, 35 dan $50 \%$ memiliki permeabilitas yang sangat rendah. Penggantian sebagian semen Portland oleh SCM akan mengurangi kalsium hidroksida bebas. SCM yang berasal dari silika amorf seperti RHA akan bereaksi dengan kalsium hidroksida bebas lebih cepat dibandingkan fly ash karena reaktifitasnya sangat tinggi (Wang et al., 2003). Hicks (2007) merekomendasikan pengurangan rasio air terhadap semen jika menggunakan fly ash kelas $C$ untuk mengatasi ASR. Selain SCM lithium merupakan unsur dalam senyawa $\mathrm{LiCl}, \mathrm{Li}_{2} \mathrm{CO}$, $\mathrm{LiF}_{2} \mathrm{Li}_{2} \mathrm{SiO}_{3}$, $\mathrm{LiNO}_{3}$ dan $\mathrm{Li}_{2} \mathrm{SO}_{4}$ yang sudah sering dipromosikan saat ini untuk mengatasi reaksi ASR (Folliard et al., 2005).

ASR yang menyebabkan keretakan pada pasta semen juga dapat dikendalikan dengan cara menggunakan agregat non-reaktif atau mencampur agregat reaktif dan non-reaktif. Jika agregat reaktif harus digunakan pada komposit semen atau beton maka SCM atau blended cement perlu digunakan untuk mengendalikan atau mengurangi ASR. Selain mengurangi konsentrasi ion $\mathrm{OH}^{-}$yang dapat menurunkan $\mathrm{pH}$ pasta semen yang selanjutnya akan mengurangi ASR maka SCM berfungsi pula mengurangi permeabilitas. SCM yang bereaksi dengan $\mathrm{Ca}(\mathrm{OH})_{2}$ akan membentuk $\mathrm{CSH}$ yang lebih 
banyak pada pori dan akan menghalangi masuknya air ke dalam pasta semen.

Peranan SCM telah terbuktidapatmeningkatkan kekuatan dan ketahanan komposit semen (Toutanji \& Danson, 2001). Penggunaan SCM pada semen Portland sebenarnya dimaksudkan untuk meningkatkan kekuatan dan ketahanan beton atau mortar dengan cara mengendalikan ASR selama proses hidrasi pasta semen (Kerenidis, 2007). Pengendalian ASR ini terjadi karena SCM berfungsi untuk mengurangi permeabilitas pasta semen dan mengurangi alkali total semen (Ballard et al., 2008). ASR yang tidak dapat dikendalikan akan menyebabkan terjadinya retak pada beton atau komposit semen lainnya yang menurunkan kekuatan dan ketahanan struktur beton atau komposit semen.

Mekanisme efek SCM terhadap ASR dijelaskan oleh Freitag et al. (2003) bahwa (a) penambahan SCM dengan kadar alkali yang lebih rendah dari semen akan mengurangi total alkali pasta semen, (b) tidak semua alkali SCM masuk ke larutan dalam pori sehingga alkali pasta semen dapat berkurang walaupun total alkali semen tidak berkurang, (c) reaksi antara $\mathrm{SCM}$ dan $\mathrm{Ca}(\mathrm{OH})_{2}$ selama proses hidrasi akan mengurangi jumlah $\mathrm{Ca}(\mathrm{OH})_{2}$ sehingga $\mathrm{pH}$ larutan dalam pori tidak meningkat sehingga mengurangi ASR, dan (d) hasil reaksi antara SCM dan $\mathrm{Ca}(\mathrm{OH})_{2}$ mengikat alkali sehingga membatasi ASR. Secara keseluruhan mekanisme ini menyebabkan pasta semen menjadi kurang permeabel sehingga mengurangi masuknya air dan mengurangi difusi alkali ke mineral reaktif.

Penggunaan abu sekam padi dengan kombinasi campuran yang sesuai pada semen akan menghasilkan komposit semen yang lebih baik (Singh et al., 2002). Abu sekam padi telah digunakan sebagai bahan pozzolan reaktif yang sangat tinggi untuk meningkatkan mikrostruktur pada daerah transisi interfase antara pasta semen dan agregat. Walaupun Sarawathy \& Song (2007) menyarankan penggunaan abu sekam padi sebesar $25 \%$ untuk membuat komposit semen tetapi penggunaan abu sekam padi sampai $30 \%$ sebagai pengganti sebagian semen masih dapat mengurangi penetrasi klorida, mengurangi permeabilitas, meningkatkan kekuatan, dan meningkatkan sifat anti karat komposit semen. Abu sekam padi telah digunakan sebagai SCM dalam pembuatan beton yang memiliki kekuatan tinggi dan permeabilitas rendah pada jembatan, bangunan dermaga, dan bangunan pembangkit tenaga nuklir karena abu sekam padi dapat meningkatkan reaksi pozzolan untuk pembentukan kalsium silikat hidrat (Dakroury \& Gasser, 2008).

\section{METODE PENELITIAN}

Bahan-bahan utama yang digunakan untuk pembuatan komposit semen ringan adalah semen Portland tipe I, abu sekam padi dan kapur sebagai campuran matriks dan sekam padi. Sebagai agregat. Semen Portland tipe I diperoleh dari salah satu perusahaan pembuat beton cetak di Maksssar, kapur diperoleh dari toko bahan bangunan dan sekam padi diperoleh dari penggilingan beras. Abu sekam padi dibuat seperti yang dilakukan oleh Harsono (2002) dan Ganesan et al. (2008) melalui beberapa penyesuaian. Instrumen penelitian terdiri atas gelas ukur, tabung reaksi, timbangan digital, baskom, ember, kantung plastik, steamer, drum bakar, ayakan, mixer, furnace tipe 1400 dan Barnsted Thermolyne. Untuk penentuan kandungan kimia bahan digunakan beberapa bahan pereaksi kimia dengan menggunakan prosedur seperti yang tercakup dalam SNI 15-2049-2004 (2004).

\section{HASIL DAN PEMBAHASAN}

Proses hidrasi semen yang berlangsung ketika mulai bereaksi dengan air hingga contoh uji memadat melibatkan berbagai aktifivas kimia dan fisika yang dapat memengaruhi karakteristik contoh uji yang dibuat dari campuran berbagai bahan. Sifat fisik dan kimia bahan yang digunakan pada komposisi campuran penyusun contoh uji perlu diketahui untuk memahami gejala yang terjadi selama aktivitas kimia dan fisika tersebut berlangsung. Sifat fisik dan kimia bahan yang digunakan dapat dilihat pada Tabel 1.

Sifat fisik dan kimia bahan pada Tabel 1 menunjukkan bahwa kerapatan gembur bahan tertinggi ke terendah yaitu semen Portland tipe I sebesar $1.250 \mathrm{~kg} \mathrm{~m}^{-3}$, abu sekam padi sebesar $760 \mathrm{~kg} \mathrm{~m}^{-3}$, kapur tohor sebesar $710 \mathrm{~kg} \mathrm{~m}^{-3}$, dan sekam padi sebesar $140 \mathrm{~kg} \mathrm{~m}^{-3}$. Kerapatan gembur merupakan kerapatan partikel butiran suatu bahan pada volume tertentu yang dipadatkan tetapi masih memiliki rongga di antara partikel-partikel butiran. Nilai kerapatan ini dipengaruhi oleh kerapatan senyawa kimia yang dominan terdapat pada bahan 
Tabel 1. Sifat Fisik dan Kimia Bahan

\begin{tabular}{|c|c|c|c|c|}
\hline \multirow{2}{*}{ Fisik dan Kimia } & \multicolumn{4}{|c|}{ Bahan } \\
\hline & Semen Portland Tipe I & Abu Sekam Padi & Kampur Tohor & Sekam Pad \\
\hline \multicolumn{5}{|l|}{ Fisik: } \\
\hline Kerapatan gembur $\left(\mathrm{kg} \mathrm{m}^{-3}\right)$ & 1.250 & 760 & 710 & 140 \\
\hline Lolos ayakan 45 m (\%) & 85 & 75 & 95 & 0 \\
\hline Tidak lolos ayakan $45 \mu \mathrm{m}(\%)$ & 15 & 25 & 5 & 100 \\
\hline Lolos ayakan $2 \mathrm{~mm}(\%)$ & - & - & - & 100 \\
\hline \multicolumn{5}{|l|}{ Komponen Kimia: } \\
\hline $\mathrm{SiO}_{2}$ (\% berat) & 22,10 & 72,28 & 0,00 & $15-20$ \\
\hline $\mathrm{Al}_{2} \mathrm{O}_{3}(\%$ berat $)$ & 5,43 & 0,37 & 2,92 & - \\
\hline $\mathrm{Fe}_{2} \mathrm{O}_{3}(\%$ berat $)$ & 3,49 & 0,32 & 1,27 & - \\
\hline $\mathrm{CaO}$ (\% berat) & 64,79 & 0,65 & 55,57 & - \\
\hline $\mathrm{MgO}$ (\% berat) & 1,18 & - & - & - \\
\hline $\mathrm{SO}_{3}(\%$ berat $)$ & 0,19 & - & - & - \\
\hline $\mathrm{Na}_{2} \mathrm{O}$ (\% berat) & 0,09 & - & 0,12 & - \\
\hline $\mathrm{K}_{2} \mathrm{O}(\%$ berat $)$ & 0,37 & - & 0,49 & - \\
\hline Bagian tak larut (\% berat) & 0,65 & - & - & - \\
\hline Kapur bebas (\% berat) & 1,50 & - & - & - \\
\hline Hilang pijar (\% berat) & 0,20 & 21,43 & 37,89 & - \\
\hline
\end{tabular}

tersebut dan volume rongga yang terdapat pada volume bahan tertentu.

Tabel 1 juga menunjukkan bahwa senyawa kimia dominan pada semen Portland tipe I yaitu $\mathrm{CaO}$ dan $\mathrm{SiO}_{2}$ sedangkan pada abu sekam padi yaitu $\mathrm{SiO}_{2}$ dan hilang pijar, dan pada kapur tohor yaitu $\mathrm{CaO}$ dan hilang pijar. Kalsium oksida $(\mathrm{CaO})$ memiliki kerapatan padat sebesar $3.341 \mathrm{~kg} \mathrm{~m}^{-3}$ sedangkan kerapatan padat $\mathrm{SiO}_{2}$ adalah sebesar $2.641 \mathrm{~kg} \mathrm{~m}^{-3}$ (Balonis \& Glasser, 2009). Walaupun senyawa $\mathrm{SiO}_{2}$ memiliki kerapatan yang lebih rendah dari $\mathrm{CaO}$ tetapi kadar $\mathrm{SiO}_{2}$ jauh lebih tinggi pada abu sekam padi dibandingkan dengan kadar $\mathrm{CaO}$ yang terdapat pada kapur tohor dan demikian pula kadar hilang pijar pada kapur tohor jauh lebih tinggi dari abu sekam padi menyebabkan kerapatan abu sekam padi sedikit lebih tinggi dari kapur tohor. Nilai kerapatan tertinggi sebesar $1.250 \mathrm{~kg} \mathrm{~m}^{-3}$ yang terdapat pada semen Portland tipe I disebabkan oleh tingginya kadar senyawa $\mathrm{CaO}$ dan $\mathrm{SiO}_{2}$ dan rendahnya kadar senyawa hilang pijar yang dikandung. Kerapatan bahan terendah yang terdapat pada sekam padi sebesar $140 \mathrm{~kg}$ m-3 tidak dipengaruhi oleh kadar senyawa kimia yang dikandung tetapi disebabkan oleh banyaknya rongga kosong yang terbentuk di antara partikel butiran sekam padi per satuan volume. Rongga- rongga kosong ini terbentuk karena bentuk partikel butiran sekam padi yang tidak teratur.

Kerapatan masing-masing bahan akan berpengaruh terhadap kerapatan komposit semen yang dibuat sesuai komposisi campuran bahan yang digunakan. Agregat ringan halus menurut ASTM C 330 adalah agregat yang memiliki berat isi maksimum $1.120 \mathrm{~kg} \mathrm{~m}^{-3}$ yang semua butiran partikelnya lolos ayakan $4,75 \mathrm{~mm}$. Dengan demikian sekam padi yang telah digiling hingga lolos ayakan 10 mesh atau $2 \mathrm{~mm}$ yang digunakan sebagai agregat dalam komposisi campuran dalam penelitian ini dapat digolongkan sebagai agregat ringan halus.

Hasil penyaringan dengan menggunakan ayakan berukuran $45 \mu \mathrm{m}$ atau 325 mesh menunjukkan bahwa persentase lolos ayakan bahan tertinggi terdapat pada kapur tohor dan semen Portland tipe I dan terendah terdapat pada abu sekam padi masing-masing sebesar 95, 85 dan 75 $\%$. Walaupun beberapa hasil analisis menunjukkan bahwa ukuran butiran partikel abu sekam padi lebih kecil dari semen Portland tipe I namun data pada Tabel 1 menunjukkan bahwa jumlah butiran partikel yang memiliki ukuran lebih besar dari $45 \mu \mathrm{m}$ atau tidak lolos ayakan $45 \mu \mathrm{m}$ lebih banyak terdapat pada abu sekam padi yaitu sebesar $25 \%$. Hal ini disebabkan abu sekam padi yang dibuat masih 
Tabel 2. Komposisi Senyawa Semen Portland Tipe I per ASTM C 150

\begin{tabular}{lcccc}
\hline Notasi Umum Semen & C3S & C2S & C3A & C4AF \\
\hline Kandungan (\%) & 55 & 19 & 10 & 7 \\
Laju Reaksi & Sedang & Lambat & Cepat & Sedang \\
Kekuatan & Tinggi & $\begin{array}{c}\text { Awal Rendah } \\
\text { Akhir Tinggi }\end{array}$ & Rendah & Rendah \\
& & & \\
\hline
\end{tabular}

Sumber: ACl (2001)

mengandung karbon terikat dalam jumlah yang cukup besar dalam senyawa hilang pijar berbentuk partikel arang halus. Di sisi lain, walaupun kapur tohor memiliki kadar karbon dalam senyawa hilang pijar yang lebih tinggi dibandingkan dengan abu sekam padi, persentase lolos ayakan $45 \mu \mathrm{m}$ pada kapur tohor masih lebih besar.

Karbon yang terdapat pada kapur tohor tersebut terdapat dalam bentuk partikel $\mathrm{CaCO}_{3}$ yang memiliki ukuran partikel lebih kecil dari partikel arang halus. Kandungan senyawa hilang pijar yang cukup besar pada abu sekam padi dapat menyebabkan berkurangnya reaktifitas silika terhadap kalsium hidroksida pada proses hidrasi. Abu sekam padi yang memiliki ukuran butiran partikel yang tidak lolos ayakan $45 \mu \mathrm{m}$ akan memiliki bentuk yang tidak teratur dan porositas internalnya sangat tinggi. Penggilingan abu hasil-hasil pertanian menjadi partikel yang halus akan memecah struktur internal partikel abu sekam padi sehingga bentuk partikelnya menjadi lebih teratur dan porositas internalnya bisa berkurang.

Jika sebagian besar senyawa abu sekam padi (di atas $90 \%$ ) terdiri atas silika $\left(\mathrm{SiO}_{2}\right)$ maka persentase lolos ayakan ukuran $45 \mu \mathrm{m}$ akan lebih tinggi dibandingkan dengan semen Portland tipe I dan kapur tohor. Hal ini terjadi karena kerapatan $\mathrm{SiO}_{2}$ sebagai senyawa dominan pada abu sekam padi lebih kecil dari kerapatan $\mathrm{CaO}$ sebagai senyawa dominan pada semen Portland tipe I dan kapur tohor. Partikel semen Portland tipe I dan kapur tohor yang memiliki ukuran lebih besar dari $45 \mu \mathrm{m}$ atau tidak lolos ayakan $45 \mu \mathrm{m}$ sebesar 15 dan $5 \%$ terjadi karena kedua bahan ini mungkin menyerap air dari udara terbuka yang terikat pada $\mathrm{CaO}$ sehingga menyebabkan terjadinya gumpalan partikel yang lebih besar. Ukuran partikel butiran bahan terutama semen Portland tipe I dan kapur tohor berpengaruh terhadap jumlah air yang dapat diserap oleh bahan pada saat proses pembuatan komposit semen. Semakin kecil ukuran butiran partikel bahan maka semakin banyak jumlah air yang dapat diserap karena luas permukaan bahan per satuan volume akan bertambah.

Persentase kandungan senyawa kimia $\mathrm{SiO}_{2}$, $\mathrm{Al}_{2} \mathrm{O}_{3}, \mathrm{Fe}_{2} \mathrm{O}_{3}$ dan $\mathrm{CaO}$ masing-masing sebesar 22,10; 5,43; 3,49 dan $64,79 \%$ pada semen Portland tipe I berpengaruh terhadap persentase fasa senyawa alite (C3S atau trikalsium silikat), balite (C2S atau dikalsium silikat), aluminate (C3A atau trikalsium aluminat) dan ferrite (C4AF atau tetrakalsium alumina ferit). Hasil perhitungan persentase fasa senyawa alite (C3S), balite (C2S), aluminate (C3A) dan ferrite (C4AF) menunjukkan bahwa persentase fasa senyawa C3S sebesar $53,82 \%$, C2S sebesar 22,76 \%, C3A sebesar 8,48\%, dan C4AF sebesar $10,62 \%$. Persentase kandungan fasa senyawa yang digunakan dalam penelitian ini masing-masing C $3 S<55 \%$, C2S $>19 \%, C 3 A<10 \%$ dan C4AF $>7$ $\%$ berdasarkan komposisi senyawa semen Portland tipe I yang ditunjukkan oleh ASTM C 150 pada Tabel 2.

Persentase kandungan fasa senyawa menunjukkan bahwa semen Portland tipe I yang digunakan cenderung memiliki laju reaksi terjadinya setting yang lebih lambat karena kandungan C3S cukup rendah tetapi dapat menghasilkan kekuatan akhir yang lebih tinggi karena kandungan fasa senyawa C2S cukup besar. Kandungan C3A yang cukup rendah dapatmeningkatkan ketahanan semen terhadap serangan sulfat sedangkan kandungan C4AF yang cukup besar akan mengurangi laju hidrasi dan membuat semen berwarna abu-abu kecoklatan. Rasio C3S:C2S yang dikandung oleh semen Portland tipe I ini sebesar 53,82 \% : 22,76 $\%$ atau 2,36 jauh lebih kecil dari rasio C3S/C2S sebesar 3 yang dikandung oleh umumnya semen Portland tipe I (Peterson et al., 2006).

Persentase $\mathrm{Na}_{2} \mathrm{O}$ sebesar $0,09 \%$ dan $\mathrm{K}_{2} \mathrm{O}$ sebesar $0,37 \%$ yang digunakan untuk menghitung $\mathrm{Na}_{2} \mathrm{O}_{\text {eq }}$ (equivalent soda) semen Portland tipe I menghasilkan nilai sebesar 0,32\%. Nilai $\mathrm{Na}_{2} \mathrm{O}_{\text {eq }}$ ini menunjukkan bahwa sifat alkalis semen Portland tipe I yang digunakan tergolong rendah karena lebih kecil dari $0,6 \%$ dan dapat digunakan sebagai matriks 
agregat yang mengandung silika. Persentase kandungan senyawa kimia semen Portland tipe I selain penting untuk menentukan jumlah persentase fasa senyawa juga digunakan sebagai indikator kesesuaian dengan standar produk semen. Semen Portland tipe I yang digunakan dalam penelitian ini memenuhi syarat persentase kandungan senyawa kimia yang ditetapkan oleh ASTM C 150.

Persentase kandungan senyawa kimia kapur tohor pada Tabel 1 menunjukkan bahwa senyawa kimia dominan pada kapur tohor yaitu $\mathrm{CaO}$ sebesar $55,57 \%$ dan hilang pijar 37,89\%. Kapur tohor tidak dapat membentuk fasa senyawa C3S maupun C2S karena walaupun mengandung $\mathrm{CaO}$ yang cukup tinggi tetapi tidak mengandung $\mathrm{SiO}_{2}$ sebagai sumber silikat pada pembentukan fasa senyawa C3S dan C2S. Pengerasan kapur tohor hanya dapat terjadi oleh adanya C3A, C4AF dan pembentukan $\mathrm{CaCO}_{3}$ setelah kapur tohor bereaksi dengan air menjadi $\mathrm{Ca}(\mathrm{OH})_{2}$ kemudian bereaksi dengan $\mathrm{CO}_{2}$. Pengerasan kapur tohor oleh $\mathrm{C} 3 \mathrm{~A}, \mathrm{C} 4 \mathrm{AF}$ dan $\mathrm{CaCO}_{3}$ tidak akan memberikan kontribusi yang berarti terhadap kekuatan semen setelah proses hidrasi berlangsung. Persentase kandungan $\mathrm{Na}_{2} \mathrm{O}$ dan $\mathrm{K}_{2} \mathrm{O}$ kapur tohor masing-masing sebesar 0,12 dan 0,49 $\%$ walaupun rendah tetapi dapat menaikkan sifat alkalis semen.

Senyawa kimia yang paling dominan terkandung pada abu sekam padi yang dibuat dan digunakan dalam penelitian ini yaitu $\mathrm{SiO}_{2}$ adalah sebesar $72,28 \%$ seperti yang ditunjukkan pada Tabel 1 . Adapun persentase kandungan senyawa $\mathrm{CaO}$ tergolong sangat rendah yaitu sebesar $0,65 \%$ yang menyebabkan abu sekam padi hanya sedikit sekali dapat menghasilkan C3S maupun C2S sehingga tidak memiliki peran yang berarti dalam pengertian semen sebagai perekat atau matriks. Jika $\mathrm{SiO}_{2}$ abu sekam padi yang cukup tinggi ini dicampur dengan semen Portland tipe I maka akan dihasilkan kalsium silikat hidrat sekunder yang dapat meningkatkan kekuatan komposit semen. Persentase kandungan senyawa hilang pijar sebesar 21,43 \% pada abu sekam padi menunjukkan bahwa jumlah karbon pada abu sekam padi cukup besar. Abu sekam padi yang dibuat pada skala industri memiliki kadar $\mathrm{SiO}_{2}$ lebih besar dari $90 \%$ dan senyawa hilang pijar lebih kecil dari $5 \%$.

Persentase $\mathrm{SiO}_{2}$ pada sekam padi sebesar 15$20 \%$ menunjukkan bahwa sekam padi jika digunakan sebagai agregat komposit semen tergolong bahan yang memiliki potensi menghasilkan reaksi alkali silika. Hasil pengujian mortar bar reaksi alkali silika sekam padi yang dilakukan oleh Bakri et al. (2010) menunjukkan bahwa persentase pertambahan panjang mortar bar rata-rata pada komposisi 40 $\%$ yang dicampur dengan semen dan tanpa kapur memiliki nilai pertambahan panjang tertinggi yaitu sebesar $0,19 \%$. Nilai pertambahan panjang mortar bar rata-rata tertinggi ke terendah yaitu pada komposisi campuran sekam padi:(semen:kapur) $40 \%:(100: 0), 30 \%:(100: 0)$, ) $40 \%:(50: 50), 30$ $\%:(50: 50), 40 \%:(75: 25)$ dan $30 \%:(75: 25)$ masingmasing sebesar 0,$19 ; 0,18 ; 0,17 ; 0,15 ; 0,13$ dan $0,12 \%$. Kriteria penggolongan reaktifitas alkali silika pada ASTM C 1260 berdasarkan pertambahan panjang mortar bar yaitu $<0,10 \%$ tergolong tidak merusak, 0,10 sampai $0,20 \%$ tergolong potensil merusak dan $>0,20 \%$ tergolong merusak (Folliard et al., 2006). Berdasarkan kriteria ASTM C 1260 ini maka semua komposisi campuran menghasilkan reaksi alkali silika yang tergolong potensil merusak. Hal ini mengindikasikan bahwa sekam padi adalah bahan agregat yang reaktif untuk menghasilkan reaksi alkali silika.

\section{KESIMPULAN}

Sifat alkali semen Portland tipe I yang digunakan tergolong rendah karena lebih kecil dari $0,6 \%$ dan dapat digunakan sebagai matriks komposit yang menggunakan agregat reaktif. Persentase silika abu sekam padi yang dihasilkan sebesar 72,28 $\%$ lebih rendah dari yang dihasilkan pada skala industri yaitu di atas $90 \%$. Persentase kandungan $\mathrm{Na}_{2} \mathrm{O}$ dan $\mathrm{K}_{2} \mathrm{O}$ kapur tohor masing-masing sebesar 0,12 dan $0,49 \%$ tergolong rendah tetapi dapat menaikkan sifat alkalis semen. Sekam padi adalah bahan agregat yang reaktif sehingga cenderung menghasilkan reaksi alkali silika. Abu sekam padi dapat digunakan sebagai bahan pengganti sebagian semen (SCM) dalam pembuatan komposit semen yang menggunakan agregat reaktif seperti sekam padi.

\section{DAFTAR PUSTAKA}

ACl. 2001. Cementitious Materials for Concrete. ACl Education Bulletin E3-01. American Concrete Institute, USA.

Bakri, Dj. Sanusi Djamal and M. Muin. 2010. ASR of Rice Husk and Potential Use of RHA to Mitigate ASR in Cement Composite. Jurnal Perennial. 6(1): 25 -32 
Ballard, Z. J., W. S. Caires and S. R. Peters. 2008. Alternate Mitigation Materials for Alkali-Silica Reaction (ASR) in Concrete. Denver, Colorado, USA: Colorado Department of Transportation, DTD Applied Research and Innovation Branch.

Balonis M. and F.P. Glasser, 2009. The Density of Cement Phases. Department of Chemistry, University of Aberdeen. Aberdeen, Scotland, UK.

Bertolini, L, B. Elsener, P. Pedeferi and R. P. Polder. 2004. Corrosion of Steel in Concrete. WILEY-VCH Verlag GmbH $\&$ Co. KGaA. Weinheim, Germany.

Dakroury, A. El. and M.S. Gasser, 2008. Rice Husk Ash (RHA) as Cement Admixture for Immobilization of Liquid Radioactive Waste at Different Temperatures. Journal of Nuclear Materials. 381: 271- 277.

Folliard, K. J., M. Juenger, A. Schindler, K. Riding, J. Poole, L. F. Kallivokas, S. Slatnick, J. Whigham and J. L. Meadows. 2005. Prediction Model for Concrete Behavior. Texas, USA: Texas Department of Transportation, Research and Technology Implementation.

Folliard, K. J., M. D. A. Thomas, B. Fournier, K. E. Kurtis and J. H. Ideker. 2006. Interim Recommendations for the Use of Lithium to Mitigate or Prevent Alkali-Silica Reaction (ASR). Report No. FHWA-HRT-06-073. McLean, USA: Infrastructure Research and Development, Federal Highway Administration.

Freitag, S. A., A. R. Goguel and N. B. Milestone. 2003. Minimising the Risk of Damage to Concrete Guidance Notes and Recommended Practice (Second Edition). Technical Report 3 (TR 3). New Zaeland: Cement and Concrete Association.

Ganesan, K., K. Rajagopal and K. Thangavel. 2008. Rice husk ash blended cement: Assessment of Optimal Level of Replacement for Strength and Permeability Properties of Concrete. Construction and Building Materials. 22 (8): $1675-1683$.

Harsono, H. 2002. Pembuatan Silika Amorf dari Limbah Sekam Padi. Jurnal Imu Dasar. 3 (2): 98 -103.

Hicks, J. K. 2007. Mitigation of Alkali-Silica Reaction while Using Highly Reactive Aggregates with Class C Fly Ash and Reduction in Water to Cementitious Ratio. Paper Presented on 2007 World of Coal Ash (WOCA), Covington, Kentucky, USA, May 7 - 10, 2007.

Ismail, M. S. and A. M. Waliuddin. 1996. Effect of Rice Husk Ash on High Strength Concrete. Construction and Building Materials. 10 (1): $521-526$
Jauberthie, R., F. Rendell, S. Tamba and I. K. Cisse. 2000. Origin of the Pozzolanic Effect of Rice Husks. Construction and Building Materials. 14: 419 - 423.

Kaboosi, K. 2007. The Feasibility of Rice Husk Application as an Envelope Material in Subsurface Drainage System. Islamic Azad University, Science and Research Branch. Tehran, Iran.

Kerenidis, K. 2007. Mitigating Alkali Silica Reaction in Concrete with Supplementary Cementing Materials When Used in Conjunction with Portland Cements Having Alkali Contents in Excess of 1.0\%. PCA R\&D Serial No. 3023. Skokie, Illinois, USA: Portland Cement Association.

Malvar, L. J. and L. R. Lenke. 2006. Efficiency of Fly Ash in Mitigating Alkali-Silica Reaction Based on Chemical Composition. ACI Materials Journal. September/October: $319-326$

MoDOT. 2003. Laboratory Study- Laboratory Testing Of Bridge Deck Mixes. Report No. RDT03-004. Jefferson City, Missouri, USA: Department of Transportation Research, Development, and Technology.

Peterson, V. K., D. A. Neumann and R. A. Livingston. 2006. Hydration of Cement: The Application of Quasielastic and Inelastic Neutron Scattering. Physica. B: 481- 486.

Saraswathy, V. and H. W. Song. 2007. Corrosion Performance of Rice Husk Ash Blended Concrete. Construction and Building Materials. 21: 1779-1784.

Singh, N. B., S. Rai and S. Chaturvedi. 2002. Hydration of Composite Cement. Progress in Crystal Growth and Characterization of Materials. 171-174.

Thomas, M. D. A., B. Fournier, K. J. Ideker and Y. Resendez. 2007. The Use of Lithium To Prevent or Mitigate AlkaliSilica Reaction in Concrete Pavements and Structures. Report No. FHWA-HRT-06-133 McLean, USA: Infrastructure Research and Development, Federal Highway Administration.

Toutanji, H. A. and A. D. Danson. 2001. Supplementary Cementitious Materials to Enhance Bridge Deck Durability. UTCA Report Number 00305. Tuscaloosa, Alabama, USA: University Transportation Center for Alabama.

Wang, L., A. Roy, R. K. Seals and J. B. Metcalf. 2003. Stabilization of Sulfate-Containing Soil by Cementitious Mixtures: Mechanical Properties. Paper Presented on TRB 2003 Annual Meeting. 